\title{
UMA REFLEXÃO SOBRE A PARCERIA DA FAMÍLIA E ESCOLA EM TEMPOS DE COVID-19: ASPECTOS PEDAGÓGICOS, ECONÔMICOS E JURÍDICOS
}

\section{REVISÃO BIBLIOMÉTRICA}

GONÇALVES, Janaína Oliveira ${ }^{1}$

MIRANDA, Maurício Fernando Oliveira de ${ }^{2}$

GONÇALVES JÚNIOR, Edson ${ }^{3}$

GONÇALVES, Janaína Oliveira. MIRANDA, Maurício Fernando Oliveira de. GONÇALVES JÚNIOR, Edson. Uma reflexão sobre a parceria da família e escola em tempos de COVID-19: Aspectos pedagógicos, econômicos e jurídicos. Revista Científica Multidisciplinar Núcleo do Conhecimento. Ano 05, Ed. 11, Vol. 06, pp. 141-154. Novembro de 2020. ISSN: 2448-0959, Link de acesso:https://www.nucleodoconhecimento.com.br/educacao/economicos-e-juridicos

\section{RESUMO}

Este artigo tem o objetivo de apresentar uma breve reflexão sobre a parceria da família e escola em tempos de COVID-19, considerando alguns aspectos pedagógicos, econômicos e jurídicos. A metodologia utilizada neste estudo é a pesquisa bibliográfica, que orienta a discussão sobre o tema, a partir dos autores que pesquisam a temática da parceria família e escola, como Coutrim, Carvalho E Almeida (2012); Barroso (2014); Rinaldi (2016), dentro outros. A reflexão pautou-se na importância do diálogo, parceria e participação da família e escola, principalmente

\footnotetext{
${ }^{1}$ Mestrado em Educação. Pós-Graduação em Metodologia do Ensino Superior; MBA em Gestão de Pessoas; Educação Infantil. Pedagogia.

${ }^{2}$ Mestre em Direito Público; Pós-graduação em Controladoria e Finanças; Contador.

${ }^{3}$ Mestre em Direito Público. Pós-graduação em Direito Público. Direito.
} 
diante da situação atípica vivida no Brasil na atualidade, devido a pandemia COVID19. Alguns aspectos pedagógicos de caráter emergencial são mencionados, assim como os possíveis impactos econômicos que afetam diretamente as instituições de ensino particulares e públicas e, a legislação vigente que orienta as medidas tomadas até o momento para a regulamentação do ensino remoto em âmbito jurídico.

Palavras-chave: Escola, família, COVID-19.

\section{INTRODUÇÃO}

A constante defesa da escola como espaço de conhecimento, socialização e vivências em parceria com a família são pontos importantes abordados neste estudo, uma vez que é imprescindível o diálogo entre educadores, familiares e estudantes, todos aqui, considerados como os protagonistas do cotidiano escolar.

O caminho dessa reflexão pauta-se em uma tentativa de compreender a relação existente entre a família e escola, principalmente como isso está ocorrendo no contexto atual, em tempos de pandemia da COVID-19. A escola, a família e os estudantes não esperavam vivenciar um período de isolamento social devido uma pandemia que se espalhou pelo mundo. Em pouco tempo, todos tiveram suas rotinas alteradas. Ficar em casa diante de um cenário de incertezas, notícias desencontradas e catastróficas tornou-se um desafio repleto de inseguranças, desconforto e prejuízos emocionais que ainda não somos capazes de calcular. Com tudo isso, dar continuidade aos estudos, sem a mediação presencial do professor não se tornou uma tarefa fácil, bem como o distanciamento físico da família para com a equipe pedagógica das instituições de ensino. De maneira repentina os estudantes se viram obrigados a se distanciarem. Muitos foram avisados pelos telejornais que não escutariam o sinal bater tão cedo, não se esbarariam com os colegas nos corredores da escola e não se abraçariam mais por algumas semanas que se seguiriam. No Brasil, desde 17 de março de 2020 as aulas na modalidade presencial estão suspensas. Caminhamos para oito meses impedidos de frequentar a escola. Embora que aos poucos os programas de combate à COVID-19 começam a sinalizar um possível retorno, caminhamos para pequenas adesões e/ou implantação de um 
ensino híbrido, no qual estudantes terão suas atividades escolares acontecendo virtualmente e presencialmente. É importante lembrar que as regras para o retorno devem seguir as orientações da OMS - Organização Mundial de Saúde, um protocolo rígido, que além das medidas de segurança e higienização, consta de sistema de rodízios entre estudantes e profissionais da educação.

Verificamos nesse momento ainda, que as escolas estão vazias; as carteiras da sala de aula, a pauta do caderno, os exercícios para serem copiados do quadro foram substituídos pela tela, pelo celular, pelo fone de ouvido e pelo sofá de casa. O pedido de silêncio para a aula continuar soa como nostalgia. Falta a rotina, falta a escola, falta a presença física do mestre que tanto tem para ensinar. Tanto para crianças e adolescentes, suas famílias e equipe da escola, o encontro, o toque, o diálogo é algo necessário, desejado, no entanto, vão ficar por um bom tempo sem acontecer da forma que todos estavam habituados.

O que sabemos é que a escola, de repente, foi transferida para o lar. Muitas instituições de ensino trataram logo de providenciar plataformas virtuais de aprendizagem, estabelecer grupos de Whatsaap e listas de transmissão de e-mails para manter a comunicação. Áudio, gravações de vídeos, envio de materiais impressos pelos correios ou em pontos de apoio foram algumas estratégias utilizadas pelas escolas. A partir deste contexto surge uma questão importante. Como está a parceria da família e a escola em tempos de COVID-19? Quais os desafios e implicações pedagógicas, econômicas e jurídicas diante desse "novo normal"? Não temos a pretensão aqui de responder essas perguntas, até porque, a realidade brasileira nos exigiria um complexo e talvez interminável levantamento de dados sobre cada realidade local, seus desdobramentos e impactos, mas entendemos que alguns aspectos discutidos nos ajudarão na compreensão da importância da parceria da família e escola para que questões de ordem pedagógica, econômica e jurídica sejam entendidas e consideradas como fundamentais para os processos escolares, de maneira que devem ser efetivadas por meio do diálogo, da partilha e da parceria, com o objetivo de minimizar os impactos, se isso é possível, diante de uma situação tão incerta para a sociedade contemporânea. 


\section{RELAÇÃO ESCOLA E FAMÍLIA: IMPLICAÇÕES PEDAGÓGICAS}

Não sem razão, o presente artigo se dedica ao estudo da relação existente entre estudantes, suas famílias e a escola ressaltando a relevância de um diálogo e parceria entre eles, mesmo diante do isolamento social, a fim de contribuir com o processo de desenvolvimento social, cultural, educacional e emocional dentro e fora do prédio escolar. Ressaltamos que ao nos referirmos à escola, estamos considerando todos os profissionais da educação, tanto professores, como coordenadores, diretores e auxiliares. No tocante às famílias, entendemos que a relação direta é estabelecida com os pais e também com os demais integrantes do núcleo familiar, conforme sua organização, considerando que muitos estudantes têm como responsáveis legais, tios, avós, primos e até mesmo tutores.

Vale ressaltar ainda, como aprofundamento para este estudo, que a relação estabelecida entre os sujeitos requer compreensão dos aspectos sociais, culturais e psicológicos. A atitude de escuta, observação e reflexão é valiosa em todos os momentos, especialmente neste contexto atual. Compreende um procedimento fundamental para que as possíveis ações sejam realizadas em favor da coletividade, tanto do ponto de vista da saúde, quanto das práticas escolares e os aspectos econômicos e jurídicos.

Sabemos que a discussão em torno da relação escola e família vem sendo feita nos últimos anos de maneira mais complexa devido seu grau de relevância no cenário educacional, uma vez que o levantamento de questões referentes ao papel da família e educadores são necessárias, como a análise da interferência ou não da escola na conduta familiar, a verificação de situações problemas enfrentadas pela escola e as causas familiares que estão por detrás de tais situações, a participação da família em situações culturais, em reuniões de pais, bem como o envolvimento com as propostas do projeto pedagógico da escola, dentre outras.

Os documentos oficiais como o Estatuto do Adolescente (ECA) e a Lei de Diretrizes e Bases (Lei 9394/96) garantem o direito de articulação das famílias com a escola, bem como o acesso dos pais e sua participação na elaboração das propostas pedagógicas 
da instituição de ensino. Porém, tal fato não garante um diálogo e uma parceria eficaz. É preciso ir além das prerrogativas legais, criando estratégias que favoreçam a interação e a parceria com vínculos duradouros e efetivos. Com a pandemia COVID19, mais do que nunca, a participação da família tornou-se fundamental. No tocante às práticas escolares voltadas para as crianças as famílias auxiliam diretamente nas questões enviadas pela escola, organizam a rotina das crianças para a realização das propostas e orientam a condução do processo. Quanto aos adolescentes, o estímulo, a motivação e o monitoramento estão ocorrendo de maneira mais intensa, por intermédio da família. Sabemos que não cabe à família fazer o papel dos professores, questão essa que foi muito discutida desde o início da pandemia. Contudo, entendemos que diante do cenário atípico vivenciado por todos, cabe cooperação, apoio e envolvimento com as propostas enviadas pela escola para garantir o desenvolvimento dos estudantes e um bom aproveitamento escolar.

Refletir sobre o papel da escola e da família nunca foi uma tarefa fácil e neste momento de paralisação das atividades presencias e realização do ensino remoto, torna-se ainda maior o desafio. A busca pela compreensão das relações de parceria entre família e escola é motivo de investigação de inúmeros pesquisadores, que retratam a relevância de valorização da relação existente entre a escola e a instituição familiar. Muitos pesquisadores buscam compreender essa relação, encontramos em Coutrim, Carvalho e Almeida (2012); Almeida (2014); Barroso (2014); Miguel e Braga (2015); Rinaldi (2016), dentre outros, reflexões sobre a temática. Tais autores demonstram de alguma maneira, como a parceria da escola e família, o diálogo com estudantes, educadores e responsáveis fomentam discussões e reflexões favoráveis para os processos administrativos, pedagógicos, filosóficos e relacionais existentes na escola.

Pensar que é possível realizar um projeto institucional, cujo diálogo e parceria entre escola e família são considerados importantes, de maneira que educadores e pais não tenham medo de se colocarem como aprendizes, como pessoas dotadas de conhecimento, cultura e informação, que aliadas, têm muito a contribuir com a gestão da escola e desenvolvimento das crianças torna-se relevante e primordial. O olhar 
atento da escola e da família para as mudanças que ocorrem nos processos educativos torna-se fundamental e a compreensão de que o espaço de relações precisa ser enriquecido dentro ou fora da escola física é o que mais tem sido propagado nos últimos tempos. Para Rinaldi (2016, p. 60), "este é o século no qual a qualidade da relação pais-filhos surgiu, pela primeira vez, como proposição teórica e como questão pública, isto é, de natureza sociocultural." A procura pela participação ativa dos pais no que tange o projeto educativo da escola mostra-se intrigante e no mínimo, provocador e necessário para continuidade das práticas pedagógicas, sejam na escola ou em casa.

Contudo, compreendemos que muitos são os entreves encontrados nesta relação escola e família, principalmente neste momento de pandemia e ensino remoto. Além disso, precisamos levar em consideração que as famílias possuem perfis diferenciados, escolarização, condições sociais e culturais distintas. Cada qual com suas expectativas e concepção do que é responsabilidade da escola e o que compete á família. Possuem também perspectivas diversas sobre o que vem a ser uma relação pautada no diálogo e "encontro" com a escola. Segundo Coutrim; Carvalho e Almeida (2014, p. 35), "para se compreender as modificações sofridas na sociedade brasileira e, consequentemente, as influências de que cada uma das três instâncias (família, política e escola) vem exercendo mutuamente, é necessário que seja feita uma contextualização histórica".

Ainda segundo Coutrim; Carvalho e Almeida (2012) a família e a escola são investigadores ativos e advém da interação social, sofrendo influências da cultura e do processo histórico no qual foram inseridos. Os autores defendem que a família e a escola são instituições fundamentais no processo de socialização dos estudantes. Para Almeida (2014), a relação entre a escola e família tem sido objeto de estudo devido sua relevância para a educação e desenvolvimento humano. Para a autora, esta relação impacta a aprendizagem das crianças e levanta uma interrogativa a respeito de implicações negativas quando há a ausência de tal interação.

A relação existente entre a família, os estudantes e a escola se dão desde muito cedo, numa rede de comunicação, convivência e parcerias. Barroso (2014) sugere um 
processo de investigação história e o perfil da família contemporânea, seu papel social e a participação na vida escolar do filho, tendo como reflexão a importância da escola e da família no processo educacional são considerados por Miguel e Braga (2015).

Nos últimos anos as famílias sofreram profundas transformações e no Brasil, não diferente de outros países no mundo, torna-se muito difícil definir um padrão de família, mas é possível a partir de dados de institutos de pesquisas e de um retorno ao contexto histórico, compreender algumas dimensões da configuração familiar existente nas escolas e, a partir daí, conhecer e se relacionar com os membros integradores do contexto escolar. Se considerarmos a escola como o local de encorajamento das relações estabelecidas não somente entre estudantes e educadores, mas também entre a família, estamos ressaltando que o espaço educativo tem a capacidade de exercer uma prática dialógica e democrática. Neste período de pandemia, novos atores se encarregaram de estabelecer a comunicação com a escola. Muitas mães em home-office delegaram funções aos filhos mais velhos e aos maridos, e vice versa. A escola entrou nas casas dos estudantes, descortinando o dia a dia familiar. De um lado, educadores sentiram-se inseguros, com receio de que os pais dariam palpites demais no trabalho pedagógico e possivelmente avaliassem as metodologias e a didática docente de forma mais atenta.

Outras dificuldades apareceram, considerando àqueles membros menos letrados. A realidade demonstra familiares sem saber o que fazer com os estudantes em casa, como orientar as tarefas ou "substituir o professor", afinal, a aula online, ministrada pelo professor em tempo real, não está acontecendo para todos. Muitos estudantes recebem cadernos com atividades e informações, podendo estabelecer contato com o professor em caso de dúvidas, mas não por meio de aulas como estavam acostumados. Outras assistem vídeos gravados, recebem áudios ou mensagens pelo telefone, sem contar àqueles que não têm acesso a nenhum desses instrumentos de apoio. Os pais e estudantes também encontraram dificuldades de organização do tempo. Ora pela sobrecarrega de trabalho home-office, ora pela quantidade excessiva de tarefas escolares, dificultando assim a organização da rotina de estudos dos filhos e demais familiares. 
No que diz respeito às atitudes políticas e culturais, muitos integrantes da família, assim como a equipe da escola desconfiaram da eficácia e de seu próprio protagonismo no tocante à participação no cotidiano escolar. Por acharem que não seriam ouvidos, por terem dificuldades de compartilhar os saberes e também opiniões usando meios não convencionais ou até mesmo por não conseguirem expressar seus medos, anseios e as questões psicológicas que ainda não sabiam como lidar se julgaram menos participativos ou desconsideraram as atuações. Contudo, segundo a educadora Rinaldi (2016) é fundamental e vitalmente importante viver numa rede de relações e comunicação, na qual se possa identificar e se beneficiar dela. Embora os desafios sejam muitos e a relação família e escola traz uma complexidade que requer estudo, pesquisa e práticas inovadoras para possibilitar a coesão, a parceria, é também possível a conexão, uma vez se for considerado que devemos lutar contra o fazer sozinho. A construção precisa ser coletiva, em favor dos estudantes, da família e da escola. O isolamento social não deve afastar a família da escola, pelo contrário, uma escola viva se faz fora de seus muros e é um trabalho de muitas mãos. "O grande valor a ser alcançado é a informação, a comunicação (...), formativa e inclusiva, de modo que ninguém seja excluído dela e na qual todo mundo trabalha junto para encontrar soluções alternativas" (RINALDI, 2016, p.89).

\section{RELAÇÃO ESCOLA E FAMÍLIA: IMPLICAÇÕES ECONÔMICAS E JURÍDICAS}

Ao refletirmos sobre a economia de uma nação, entendemos que esse país possui por si só uma dinâmica própria, com questões regulares, sendo considerado, de períodos em períodos, movimentos ascendentes e descendentes, formando assim o que chamamos de ciclos econômicos. Os ciclos econômicos podem acontecer de tempos em tempos, conforme expressa o economista russo Nikolai Kondratiev (1892 - 1938). Basicamente, quando o ciclo está posicionado em sua ascensão, existem fatores que se destacam na economia, como o aumento do emprego, da renda e a capacidade para o consumo, estabilizando a economia e gerando prosperidade. Quando a economia atinge o cume do gráfico, a tendência é começar a cair, gerando assim as famigeradas crises econômicas. 
Sobre ciclos econômicos, Jonh M. Keynes (1996, p. 217), explica que:

Por movimento cíclico queremos dizer que, quando o sistema evolui, por exemplo, em direção ascendente, as forças que o impelem para cima adquirem inicialmente impulso e produzem efeitos cumulativos de maneira recíproca, mas perdem gradualmente a sua potência até que, em certo momento, tendem a ser substituídas pelas forças que operam em sentido oposto e que, por sua vez, adquirem também intensidade durante certo tempo e fortalecem-se mutuamente, até que, alcançado o máximo desenvolvimento, declinam e cedem lugar às forças contrárias.

As crises não podem ser medidas simplesmente pelo tempo, existem outros fatores que causam crises econômicas e que podem comprometer todo o sistema, causando problemas graves financeiros. Em suma, as crises econômicas e financeiras são frutos de vários fatores que aconteceram em um ou mais países. Considerando um mundo globalizado, o efeito borboleta é inevitável.

Neste cenário pandêmico, a COVID-19 instalada no Brasil e no mundo desde o fim de 2019, trouxe com ela, além dos terríveis problemas de saúde pública e isolamento social, um problema econômico e financeiro que tem refletido diretamente na educação do país, especialmente no Brasil. Em decorrência do fechamento temporário das empresas determinada pelos Governos durante a pandemia, a consequência imediata foi o desemprego, causando assim forte desestabilidade no setor da Educação, fazendo com que muitas escolas privadas encerrassem suas atividades, assim como outros segmentos. De acordo com a pesquisa realizada pelo Instituto Brasileiro de Geografia e Estatísticas - IBGE (junho 2020), quase 40\% das empresas brasileiras, de um total de 1,3 milhão, encerraram suas atividades desde 0 início da pandemia.

O impacto fiscal da COVID-19 na educação advém de duas fontes: de um lado temos a paralisia geral ou parcial das atividades econômicas, gerando assim queda na arrecadação tributária e desemprego, trazendo queda na renda familiar. Com o aumento do desemprego e a falta de renda familiar, apontamos a segunda fonte do impacto fiscal, o aumento das despesas geradas pelo setor público de educação, uma vez que haverá aumento de alunos oriundos da rede privada na rede pública de ensino. A migração destes alunos poderá acarretar um aumento substancial das 
despesas, haja vista que será necessário aumento no quadro de professores e servidores que lidam diariamente com a educação.

O financiamento da educação pública no Brasil é constituído de uma série de fontes tributárias (impostos e transferências) expressas na Constituição da República de 1988. O artigo 212 da Carta Magna determina que a União não poderá aplicar menos que $18 \%$ das receitas oriundas de impostos e transferências e os Estados, Munícipios e o Distrito Federal não poderão aplicar menos que $25 \%$ das fontes mencionadas. Desta forma, a educação básica no Brasil somente pode ser financiada com base no que é recolhido dos impostos das empresas. Basicamente os impostos e transferências vinculadas à educação são: ICMS - Imposto sobre Circulação de Mercadorias e Serviços (estadual); o ISSQN - Imposto sobre Serviços de Qualquer Natureza (municipal); o FPM - Fundo de Participação dos Municípios e o FPE - Fundo de Participação dos Estados (ambos são transferências da União - Art. 159 C.R).

A capacidade de subsidiar a educação básica no Brasil está ligada diretamente ao nível agregado de recolhimento de tributos, que obviamente, são feitos através de empresas privadas. Com a queda brusca de faturamento das empresas durante 0 período da pandemia, consequentemente haverá uma queda proporcional de arrecadação e recolhimento de tributos, gerando assim uma crise econômica na educação.

Segundo estudo realizado pelo Banco Mundial[4], o comportamento da economia brasileira em 2020 poderá ser de uma retração de até $-5 \%$ em relação ao PIB Produto Interno Bruto. Em maio deste ano, o governo revisou sua meta para o PIB de 2020, apontando uma redução de 4,7\%. Neste cenário pessimista, a econômica trabalha da seguinte forma: haverá uma desaceleração nos meios de produção (produtos e serviços), fechamento de empresas, desemprego e menor recolhimento de tributos. A consequência é justamente uma menor taxa de investimento feito na educação básica. Em suma: Haverá uma queda substancial de receitas e um aumento relevante de despesas no setor da educação básica brasileira. Desta forma, a parceria da família com a instituição escolar será de grande valia, pois todos precisarão unir forçar e buscar estratégias para socorrer a escola privada e também pública em nosso 
país. Entendemos desta forma, que para além da relação escola-família, essa é uma situação intersetorial que requer uma ação que necessitará de uma interação de outros órgãos e setores sociais, econômicos e jurídicos.

$\mathrm{Na}$ perspectiva das relações e trabalho coletivo, a escola se vê atrelada à processos jurídicos para o funcionamento de suas atividades e validação de seus processos. $\mathrm{E}$ se vê diante de um cenário econômico que impacta já em 2020 as redes de ensino privadas e consequências na esfera pública, municipal e estadual.

No tocante aos pareceres jurídicos as instituições de ensino estão amparadas pela legislação vigente. Muitas resoluções e pareceres circularam em âmbito nacional desde a deliberação do Comitê Extraordinário COVID-19 no dia 22 de março de 2020. O Conselho Estadual de Educação, seguindo orientação do Conselho Nacional, passou a orientar as Secretarias Estaduais de Educação em cada região, seguido pelo município, juntamente com os sindicatos de escolas particulares em todo Brasil. Notas de esclarecimentos e orientações passaram a fazer parte do cotidiano, de maneira que as escolas ao receberem e após detalhada análise, repassaram paras as famílias, como forma de justificativa, embasamento e autorização para a realização de ações tomadas pelas instituições de ensino. Tais medidas atualmente estão respaldadas pela Lei no $\mathbf{1 4 . 0 4 0}$, de 18 de agosto de 2020, que estabelece normas educacionais excepcionais a serem adotadas durante o estado de calamidade pública reconhecido pelo Decreto Legislativo ํㅡ 6, de 20 de março de 2020; e altera a Lei $n^{-}$ 11.947, de 16 de junho de 2009. A Lei prevê nos artigos 1 e 2 que,

Art. $1^{\circ}$ - Parágrafo único. O Conselho Nacional de Educação (CNE) editará diretrizes nacionais com vistas à implementação do disposto nesta Lei.

Art. 2ํㅡㄹ Os estabelecimentos de ensino de educação básica, observadas as diretrizes nacionais editadas pelo CNE, a Base Nacional Comum Curricular (BNCC) e as normas a serem editadas pelos respectivos sistemas de ensino, ficam dispensados, em caráter excepcional:

I - na educação infantil, da obrigatoriedade de observância do mínimo de dias de trabalho educacional e do cumprimento da carga horária mínima anual previstos no inciso II do caput do art. 31 da Lei no 9.394, de 20 de dezembro de 1996; 
II - no ensino fundamental e no ensino médio, da obrigatoriedade de observância do mínimo de dias de efetivo trabalho escolar, nos termos do inciso I do caput e do $\S 1^{\circ}$ do art. 24 da Lei $n^{\circ}$ 9.394, de 20 de dezembro de 1996, desde que cumprida a carga horária mínima anual estabelecida nos referidos dispositivos, sem prejuízo da qualidade do ensino e da garantia dos direitos e objetivos de aprendizagem, observado o disposto no $\S 3^{\circ}$ deste artigo". (Lei 14040 de 2020).

A Lei 8.142/90 traz ainda orientações para os cursos de educação profissional nível médio e também menciona o retorno às atividades escolares regulares.

Art. 4 Ficam os sistemas de ensino autorizados a antecipar, em caráter excepcional, a conclusão dos cursos de educação profissional técnica de nível médio, desde que diretamente relacionados ao combate à pandemia da Covid-19, observadas as normas a serem editadas pelo respectivo sistema de ensino, caso o aluno cumpra, no mínimo, $75 \%$ (setenta e cinco por cento) da carga horária dos estágios curriculares obrigatórios.

Art. 6o $O$ retorno às atividades escolares regulares observará as diretrizes das autoridades sanitárias e as regras estabelecidas pelo respectivo sistema de ensino (Lei 14040 de 2020).

A partir das diretrizes nacionais, o Conselho Estadual de Educação apresentou em cada região do Brasil as principais orientações de reorganização das atividades escolares, previstas na legislação vigente a serem adotados nas escolas. Os documentos, de uma forma geral, mencionaram os seguintes itens:

- Reorganização das atividades escolares;

- Planejamentos das atividades pedagógicas não presenciais;

- Reorganização do calendário escolar;

- Uso dos meios digitais;

- Comunicação família e escola;

- Registros;

- Acompanhamento aos estudantes pela unidade escolar;

- Avaliações;

No momento atual, temos a liberação de diversos protocolos de segurança sendo elaborados e outros colocados em prática, que tem por finalidade orientar a 
comunidade escolar a cerca dos procedimentos relacionados ao comportamento e conduta de famílias, estudantes, professores e funcionários perante o retorno presencial gradual das atividades escolares, por meio de medidas de segurança que propiciem um ambiente saudável e organizado. No entanto, enquanto algumas escolas estão se preparando para a retomada de suas atividades, o CNE - Conselho Nacional de Educação aprovou em 06 de outubro de 2020 a validade do ensino remoto até o dia 31 de dezembro de 2021. O prazo foi estendido e as redes de ensino podem substituir as aulas presenciais por atividades remotas até essa data.

Caberá desta forma, bastante diálogo e participação da comunidade escolar - escola, estudantes e famílias - para os próximos desdobramentos ocasionados pela pandemia - COVID-19.

\section{CONSIDERAÇÕES FINAIS}

Consideramos que as reflexões apresentadas trouxeram uma pequena explanação de uma dimensão muito maior. Aqui, buscamos evidenciar apenas alguns pontos relevantes a respeito da participação da família e escola em tempos de COVID-19 e entendermos ser um "ponta pé" inicial de uma longa discussão, análise e reflexão a respeito de muitos desdobramentos.

A relação família e escola se apresenta como desafiante, contudo, é necessário fomentar a discussão sobre a importância de proporcionar o direito à escuta, partilha, diálogo, partindo de uma concepção que considera estudantes, familiares e membros da escola, indivíduos potenciais, que possuem tanto direito, como deveres e estão em busca de interesses coletivos. Consideramos que a família é uma instituição que tem um papel fundamental nesta construção, assim como a escola, principalmente neste cenário atual, em tempos de pandemia - COVID-19.

Os impactos econômicos que a escola já vem sofrendo, juntamente com as questões emocionais que vem afetando toda a sociedade, é uma realidade e nos mostra o quanto é necessário neste momento estreitar laços, caminhar em parceria, estabelecendo a participação da família nas decisões escolares e, que impactarão a 
vida dos estudantes nas próximas décadas. Os processos jurídicos além de servirem como orientadores e regulam os procedimentos, mas para além de tais normas e leis previstas na legislação escolar atual, a situação requer maior apoio, tanta da família, dirigentes escolares, políticos e demais setores. O que sabemos com maior precisão na atual conjuntura é que precisamos estar juntos no enfrentamento da COVID-19, tomando ações mais assertivas possíveis agora, em busca de maior esperança no por vir.

\section{REFERÊNCIAS}

ALMEIDA, E.B. A relação entre pais e escola: A influência da família no desempenho escolar. 2014. Faculdade de Educação da Universidade Estadual de Campinas. Campinas, 2014.

BARROSO, G.P. Tecendo ideias sobre a importância da relação família e escola na infância. 2014. Universidade Federal do Estado do Rio de Janeiro. Rio de janeiro, 2014.

BRASIL. Constituição (1988). Constituição da República Federativa do Brasil. Disponível:

http://www.senado.gov.br/atividade/const/con1988/CON1988_15.09.2015/i nd.asp. Acesso em: 19 out. 2020.

BRASIL, Lei Federal no 14.040, de 18 de agosto de 2020. Estabelece normas educacionais excepcionais a serem adotadas durante o estado de calamidade pública.

COUTRIM, R.M.E.; CARVALHO, R.A.; ALMEIDA, J.P.P. Relação escola e família: Uma construção Sócio- Histórica. 2012. Cadernos de História e Educação, v. 11, n.2, julho/dezembro de 2012.

KEYNES, J. M. A teoria geral do emprego, do juro e da moeda. São Paulo: Abril Cultural, 1983. 
MIGUEL, L.O.S.; BRAGA, E.R.M. A importância da família no processo de aprendizagem, visando ao sucesso escolar. 2015. Disponível em http:// www.diaadiaeducacao.pr.gov.br. Acesso em 10 de setembro de 2016.

RINALDI, C. Diálogos com Reggio Emília. Rio de Janeiro/São Paulo: Paz e Terra, 2016, p. 09-98.

\section{APENDECÊ DE RODAPÉ}

[4] Estudo publicado em 12 de abril de 2020. Disponível em: https://openknowledge.worldbank.org/hand-le/10986/33555

Enviado: Novembro, 2020.

Aprovado: Novembro, 2020. 